\title{
B-lymphoblastic leukaemia presenting as autoimmune haemolytic anaemia
}

\author{
Dries Deeren
}

Received: 3 September 2008 / Accepted: 23 September 2008 / Published online: 7 October 2008

(C) Springer-Verlag 2008

\section{Dear Editor,}

In the March 2008 issue of Annals of Hematology, Niscola and colleagues reported a case of B-lymphoblastic leukaemia 9 months after the diagnosis of autoimmune haemolytic anaemia (AIHA) [1].

The preceding AIHA was in remission and its treatment was stopped, so nor the preceding AIHA nor its treatment influenced the leukaemia treatment. However, when Blymphoblastic leukaemia presents immediately as AIHA, treatment should be directed against both leukaemia and haemolysis, and toxicity should be limited.

Recently, a 61-year-old man was admitted to the emergency department because of dyspnoea. The Hb count was $6.7 \mathrm{~g} / \mathrm{dl}$, WBC count $1.2 \cdot 10^{9} / 1,5.8 \%$ blasts, neutrophil count $0.3 \cdot 10^{9} / 1$, platelet count $84 \cdot 10^{9} /$. Despite a normal reticulocyte count, there was evidence of relevant haemolysis suggested by increased lactate dehydrogenase and indirect bilirubin, and decreased haptoglobin. The peripheral blood smear showed no schistocytes. The direct antiglobulin (Coombs') test was positive (3+) with polyvalent antibodies and anti-C3d, and negative with anti-IgG. Testing for cold agglutinins was negative. Bone marrow examination showed a common acute lymphoblastic leukaemia (ALL) with 97.5\% marrow blasts and a normal karyotype.

Because he had a history of myocardial ischemia, packed cells were transfused. This caused a very modest $\mathrm{Hb}$ increase. Because of neutropenia and the expectation of several more weeks of neutropenia and mucositis, we

\section{Deeren $(\bowtie)$}

Department of Haematology,

Heilig-Hartziekenhuis Roeselare-Menen vzw,

Wilgenstraat 2,

8800 Roeselare, Belgium

e-mail: DDeeren@hhr.be wanted to reduce the amount of corticosteroids. We chose to start preinduction treatment for ALL with cytarabine, etoposide and methotrexate. After 1 month, the Coombs' test was only slightly positive, and laboratory evidence of haemolysis had disappeared. Induction therapy for ALL was started, this time with corticosteroids (dexamethasone), vincristine and adriamycin. One month later, the Coombs' test was negative. After the induction courses, the $\mathrm{Hb}$ started to increase. A complete remission of ALL was achieved. After consolidation with cytarabine and asparaginase, the patient was admitted for allogeneic stem cell transplantation.

Cases of ALL with a positive Coombs' test at the time of diagnosis have been reported [2]. All had a positive Coombs' with anti-Cd3 but not with anti-IgG, and cold agglutinins could not be found. In these patients, the Coombs' test became negative when complete remission was achieved.

Even though cytostatic drug are immunosuppressive, corticosteroids are most often used as first-line therapy for haemolytic anaemia caused by warm antibodies. Our results suggest that corticosteroids may not be necessary in the initial treatment of AIHA caused by ALL, as long as effective treatment directed against ALL is started.

\section{References}

1. Niscola P, Scaramucci L, Perrotti A, Fratoni S, Piccioni D, Tendas A, Cupelli L, Dentamaro T, Del Poeta G, de Fabritiis P (2008) Acute lymphoblastic leukemia subsequent to autoimmune hemolytic anemia: a case report. Ann Hematol 87:237-238 doi:10.1007/ s00277-007-0370-y

2. Solal-Celigny P, Vazeux R, Vroclans M, Amar M, Herrera A, Bernard JF, Boivin P (1984) Positive Coombs test in acute leukaemia. Br J Haematol 57:563-569 